TEATRO

\section{SHAKESPEARE VIVE}

Durante sua vida, William Shakespeare publicou 38 peças e 154 sonetos, além de dois longos poemas narrativos. 400 anos após sua morte, a obra do dramaturgo inglês continua emocionando, suscitando debates e estudos e cativando um público gigantesco ao redor do mundo. Para homenagear um dos maiores nomes da cultura mundial, o British Council, em parceria com a embaixada do Reino Unido e o programa Visit Britain, organizou o Shakespeare lives (Shakespeare vive), iniciativa mundial que apresenta ao público diversas atividades culturais e educativas para promover a imagem de um Shakespeare contemporâneo e criativo.

Os eventos serão disseminados em 110 países - inclusive no Brasil - e a programação contará com espetáculos de dança e teatro, exibiçõoes de filmes, exposições de arte, festivais internacionais, cursos online, torneios teatrais e a publicação de conteúdos educacionais para o ensino da língua inglesa. Os apreciadores do dramaturgo inglês podem fazer um curso online de inglês grátis baseado em sua vida.

Outro destaque é o lançamento de uma plataforma online em que pessoas do mundo todo poderão interpretar cenas das peças de Shakespeare de forma criativa, recriando suas obras no meio digital. "A herança de Shakespeare não tem comparação: as suas obras foram traduzidas em
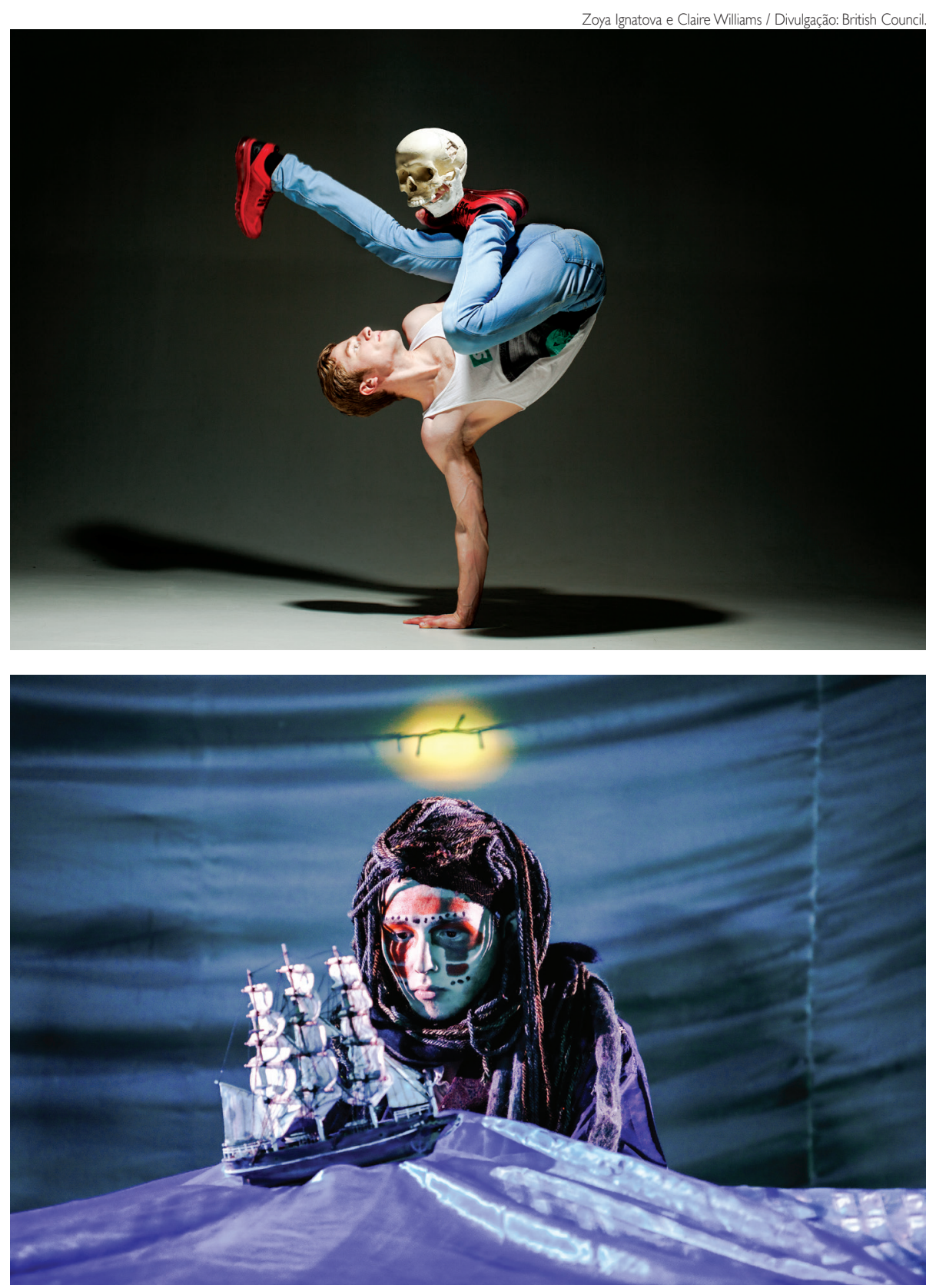

Comemorações em torno do dramaturgo inglês incluíram um concurso de fotografias com novas leituras sobre sua obra

mais de 75 línguas e são estudadas por alunos de metade do planeta”, afirmou o primeiro-ministro do Reino Unido, David Cameron, no lançamento do programa. A programação pode ser acessada no site oficial do evento: www.shakespearelives.org.
No Brasil a cidade de Curitiba foi o palco do lançamento do programa, que aconteceu em março, paralelamente ao Festival de Teatro de Curitiba, um dos mais tradicionais do país. Entre as atividades que acontecem no país ao longo de todo o ano de 2016 está a Casa Shakespeare, em 
Paraty, durante a Flip, maior festival literário do Brasil, e uma programação de teatro e de filmes do acervo do British Film Institute em diversas cidades do país. O legado de Shakespeare também é tema da campanha educacional online Play Your Part e de atividades na British House, a casa britânica no Rio de Janeiro, durante os Jogos Olímpicos.

Também um concurso para professores e alunos dos ensinos fundamental 11 e médio, chamado "Shakespeare hoje", que vai estimular os alunos a pensar criticamente sobre a relevância do autor no contexto atual. A iniciativa contará com material pedagógico elaborado pelo British Council em parceria com a Royal Shakespeare Company, em português. Haverá, também, distribuição gratuita de materiais didáticos para o ensino de inglês com a temática de Shakespeare.

FAZENDO HISTÓRIA William Shakespeare nasceu em 1564 e foi criado em Stratford-upon-Avon, uma pequena cidade no interior da Inglaterra, mas mudou-se para Londres por volta de 1588 , onde começou sua carreira como ator e escritor. Não demorou muito para que seu trabalho fosse reconhecido, tanto pela qualidade quanto pelo aspecto inovador. "Na virada do século XVI para o XVII, Shakespeare era $\mathrm{o}$ artista mais celebrado e famoso da corte elisabetana em razão da fluidez e da força metafórica de seus textos, bem como da argúcia nas montagens e performances de palco", diz Aparecido Donizete Rossi, chefe do Departamento de Letras Modernas da Universidade Estadual Paulista Júlio de Mesquita Filho (Unesp).
Visionário, Shakespeare escreveu peças dentro de peças, como em Hamlet. Em Macbeth contou a história de seu país usando metáforas e ironia. Inventava palavras para designar o que a língua inglesa daquele tempo ainda não era capaz de comportar, transformava instruçóes para atores e descrições de palco em texto das peças. Esses são apenas alguns dos artifícios introduzidos pelo autor no teatro de sua época e que permanecem inovadores ainda hoje. Shakespeare produziu a maior parte de suas obras entre 1590 e 1613 . No final de sua vida, voltou paraStratford-upon-Avon, onde morreu em 23 de abril de 1616. A obra do dramaturgo começou a se tornar conhecida em outros países e a notoriedade do escritor atingiu seu ápice no século XIX, com o romantismo, atése tornar hoje um dos maiores nomes da cultura mundial. "Eu diria que Shakespeare não tinha medo de representar os extremos. Ele viveu em uma época de transição, na qual ainda restavam fortes elementos do feudalismo, mas já despontavam as forças que levariam à era moderna. A coexistência de mundos opostos solapava um chão seguro à composição. Sua disposição de ir até onde a imaginação consegue é um exemplo valioso para o nosso tempo, no qual há tantos autores preocupados com a sua imagem, sempre procurando agradar ao público e às editoras, sem disposição de enfrentar o mercado", afirma Fábio Akcelrud Durão, professor de teoria literária do Instituto de Estudos da Linguagem da Unicamp.

UNIVERSAL "As peças de Shakespeare permanecem atuais porque cada uma delas, especialmente as mais co- nhecidas, tematiza valores universais plasmados em personagens emblemáticas. Hamlet é uma peça sobre a vingança, Macbeth sobre a ganância, Otelo trata do ciúme e Romeu e Julieta sobre o amor", explica Rossi. E continua: "Shakespeare soube, como nenhum outro artista, captar essas bases personificando-as e nomeando-as, tornando-as personagens, representaçôes verossimilhantes do humano. Ocorre, no entanto, que Shakespeare foi além e tornou essas personagens arquétipos do que representam. É dessa capacidade de tornar arquetípicos os sentimentos mais profundos da condição humana que emerge a atualidade de Shakespeare".

Já para Durão, a atualidade de Shakespeare surge por uma via diferente. "É justamente quando percebemos como suas peças combinam elementos estranhos a nós com outros que ainda ressoam, que aparece algo poderoso sobre o nosso presente. Algo semelhante acontece quando nos deparamos com o acúmulo de séculos de leituras e intepretações de seus textos. Neste caso, temos um palco no qual diferentes épocas aparecem e com as quais podemos contrastar a nossa”.

Independentemente do motivo, éinegável a atração que a obra shakespeariana desperta em seus leitores e espectadores, assim como a marca indelével que o dramaturgo e poeta deixou na história do mundo. Suas obras transcendem ao longo dos séculos como patrimônio mundial. Por isso, 400 anos depois da sua morte, ele é celebrado como um escritor vivo que ainda fala para todos os povos e nações.

Chris Bueno 